Check for updates

Cite this: RSC Adv., 2017, 7, 44923

Received 3rd July 2017

Accepted 6th September 2017

DOI: $10.1039 / \mathrm{c} 7 \mathrm{ra07318f}$

rsc.li/rsc-advances

\section{Effect of strain-induced martensite on the tribocorrosion of AISI 316L austenitic stainless steel in seawater}

\author{
Eryong Liu, (D) *ac Yingxin Zhang, ${ }^{\mathrm{b}}$ Lufa Zhu, ${ }^{\mathrm{c}}$ Zhixiang Zeng ${ }^{\star c}$ and Ruipeng Gao ${ }^{\mathrm{d}}$
}

Strain-induced phase transformation of austenite into martensite often results in the hardening and strengthening of metastable austenite stainless steel; thus, pin-on-disc friction experiments were carried out to investigate the effect of strain-induced martensite on the tribocorrosion of AISI 316L austenitic stainless steels in artificial seawater. The obtained results demonstrate that high load is beneficial for the formation of strain-induced martensite, which is closely related to the improvement of hardness and wear resistance of AISI 316L. Macroscopic and microscopic galvanic corrosion products were formed by martensite and austenite retained on the worn surface during sliding. Therefore, the total mass loss of $316 \mathrm{~L}$ in artificial seawater was mainly due to mechanical wear and the synergistic effect of corrosion on wear, particularly at high load conditions. Thus, the tribocorrosion behavior of austenitic stainless steel was dominated by the formation and corrosion of strain-induced-martensite with metastable austenite.

\section{Introduction}

Austenitic stainless steels, particularly for AISI 316L, exhibit an attractive combination of high corrosion resistance and superior mechanical properties in marine atmosphere or seawater conditions. Therefore, austenitic stainless steels are widely used in marine equipment, such as pumps, vessels, pipes, impellers, and other type of components. ${ }^{1-5}$ In corrosive environments, corrosion resistance of austenitic stainless steels is related to the formation and breakdown of passive films. ${ }^{6,7}$ Nevertheless, many types of components such as propellers, anchors and valves are not only subjected to the static corrosion conditions but also to the combination of corrosion and wear conditions (tribocorrosion). During the tribocorrosion process, the wear damage could lead to the breakdown or removal of passive film from the contact area; thus, the damage caused due to static corrosion and pure mechanical wear is significantly lower than the damage of tribocorrosion. ${ }^{\mathbf{8} 9}$ Under this condition, the total damage of the metal is accelerated due to the role of wear-

${ }^{a}$ School of Materials Science and Engineering, Xi'an University of Science and Technology, Xi'an 710054, China. E-mail: ley401@163.com; Fax: +86-29-85587373; Tel: $+86-29-85587373$

${ }^{b}$ School of Materials and Chemical Engineering, Ningbo University of Technology, Ningbo 315211, China

'Key Laboratory of Marine Materials and Related Technologies, Zhejiang Key Laboratory of Marine Materials and Protective Technologies, Ningbo Institute of Materials Technology and Engineering, Chinese Academy of Sciences, Ningbo, 315201, China. E-mail: zengzhx@nimte.ac.cn; Fax: +86-574-86685159; Tel: +86574-86685809

${ }^{d}$ School of Mechanical and Precision Instrument Engineering, Xi'an University of Technology, Xi'an 710048, China accelerated-corrosion or corrosion-accelerated-wear. Therefore, the tribocorrosion properties of the components would affect the service quality of equipment in corrosive environments.

In general, tribocorrosion is a widespread phenomenon in many engineering situations, particularly in marine equipment. During the tribocorrosion process, the total damage to materials is composed of mechanical wear, corrosion and synergistic effects between corrosion and wear. ${ }^{\mathbf{1 0 - 1 2}}$ In general, corrosion resistance is associated with the protective passive film; thus, the passive metals such as $\mathrm{Al}$, Ni or stainless steel, usually have better corrosion resistance. In addition, wear resistance is closely related to the hardness of materials; thus, the actual application of austenitic stainless steel in moving parts under corrosive solutions is restricted, due to its relatively low hardness. ${ }^{13-15}$ Therefore, increasing the hardness of the contact area is the key to improving the tribocorrosion properties of passive metals, such as AISI 316L. Various methods are available to improve the hardness of austenitic stainless steels, such as precipitation hardening, work hardening, second phase strengthening and grain refinement. ${ }^{16-21}$ Among these methods, the formation of strain-induced martensite is an effective method for the hardening treatment of austenitic stainless steels. ${ }^{22,23}$ It is understood that martensite could be mechanically induced from the austenite phase if the latter is retained in a metastable state, and type AISI 316L consists of metastable $\gamma$-austenite at room temperature. In addition, the formation of martensite is beneficial for the improvement of the hardness or mechanical behavior of austenitic steel, which could be caused due to surface treatments, severe forming processes or deformation. ${ }^{24-26}$ Nevertheless, many studies are highly focused on 
the effect of strain-induced martensite on the mechanical properties of austenitic steel. However, there is little research referring to the influence of strain-induced martensite on the tribocorrosion behaviors of austenitic steel in corrosive solutions. Thus, the formation of martensite of AISI 316L during sliding in corrosive solutions and the influence of straininduced martensite on the corrosion, wear and tribocorrosion has attracted the interest of a large number of researchers. Therefore, the aim of the present study is to investigate the effect of strain-induced martensite on the tribocorrosion of austenitic steel in seawater. In addition, special attention is paid to the volume fraction of martensite transformations after sliding wear in seawater under different loadings. This study provides a more comprehensive view for understanding the tribocorrosion mechanism of austenitic steel in seawater.

\section{Experimental}

\subsection{Materials}

AISI 316L stainless steel (chemical composition: $\mathrm{C} \leq 0.03$, $\mathrm{Si}$ $\leq 1.0, \mathrm{Mn} \leq 2.00, \mathrm{P} \leq 0.045, \mathrm{~S} \leq 0.030$, Ni: 10.0-14.0, Cr: $16.0-$ 18.0, Mo: 2.0-3.0, Fe: balance) was selected as the test material. Before tribocorrosion tests, the 316L pin samples were $6 \mathrm{~mm}$ in diameter and $4 \mathrm{~mm}$ in thickness, and alumina specimens of dimensions $18 \mathrm{~mm} \times 18 \mathrm{~mm} \times 5.3 \mathrm{~mm}$ were selected as the disc material. After polishing, the specimens were ultrasonically cleaned in acetone (10 $\mathrm{min}$ ) and ethanol (10 $\mathrm{min})$, and then dried with nitrogen gas.

Artificial seawater was prepared according to the standard procedure described in ASTM D 1141-98. The $\mathrm{pH}$ of artificial seawater was adjusted to $8.20 \mathrm{using} 0.1 \mathrm{~mol} \mathrm{~L}^{-1} \mathrm{NaOH}$ solution.

\subsection{Tribocorrosion}

The tribocorrosion tests were carried out using a pin-on-disk reciprocating tester (Rtec, America) equipped with an electrochemical workstation (Modulab, America), and the schematic of tribocorrosion tests is shown in Fig. 1. During testing, the corrosion behavior of $316 \mathrm{~L}$ was measured using the classic three electrode system of the electrochemical workstation. Ag/ $\mathrm{AgCl}$ (saturated KCL solution) was used as the reference electrode, Pt wire with a diameter of $1 \mathrm{~mm}$ was used as the counter electrode, and the 316L sample was used as the working electrode. The tribocorrosion tests of $316 \mathrm{~L}$ were conducted under tribocorrosion conditions and pure mechanical wear conditions (cathodic protection) with different loadings. The normal load was raised from $100 \mathrm{~N}, 300 \mathrm{~N}$ or $500 \mathrm{~N}$, and the corresponding contact stress was $3.54 \mathrm{MPa}, 10.62 \mathrm{MPa}$, and $17.69 \mathrm{MPa}$, respectively. All the tribocorrosion tests were conducted at the reciprocating speed of $20 \mathrm{~mm} \mathrm{~s}^{-1}$ (contact frequency of $2 \mathrm{~Hz}$ ); the friction coefficient was recorded in real-time. In addition, in order to eliminate the electrochemical corrosion of the $316 \mathrm{~L}$ sample, a cathodic protection $(-0.8 \mathrm{~V})$ was applied primarily during the tribocorrosion tests. The mass loss of 316L protected by cathodic protection was identified as the pure mechanical wear. After testing, the wear rate of $316 \mathrm{~L}$ was calculated using the following eqn (1):

$$
W=\frac{m}{(\rho \times F \times S)}
$$

In this equation, $W$ is the wear rate, $m$ is the mass loss, $\rho$ is the density of AISI $316 \mathrm{~L}, F$ is the applied load and $S$ is the total sliding distance.

Table 1 Electrochemical measurement results of AISI 316L after sliding under different loads in artificial seawater

\begin{tabular}{lllll}
\hline Load $/ \mathrm{N}$ & $0 \mathrm{~N}$ & $100 \mathrm{~N}$ & $300 \mathrm{~N}$ & $500 \mathrm{~N}$ \\
\hline$E_{\mathrm{corr}} / \mathrm{V}$ & -0.269 & -0.351 & -0.410 & -0.421 \\
$E_{\mathrm{pit}} / \mathrm{V}$ & 0.489 & 0.310 & 0.305 & 0.303 \\
$I_{\text {corr }} / \mu \mathrm{A}$ & $0.696 \times 10^{-1}$ & 0.117 & 0.332 & 0.354 \\
$B_{\mathrm{a}} / \mathrm{mV} \mathrm{dec}^{-1}$ & 89.85 & 49.50 & 98.93 & 106.20 \\
$B_{\mathrm{c}} / \mathrm{mV} \mathrm{dec}^{-1}$ & -48.69 & -34.11 & -56.00 & -43.00
\end{tabular}

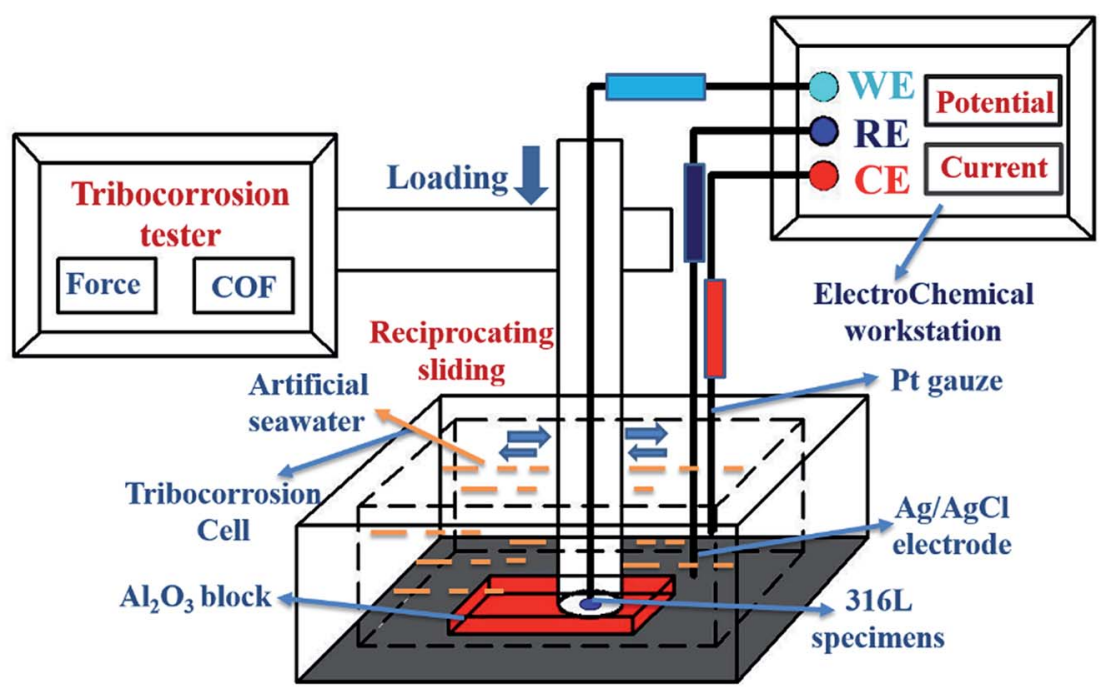

Fig. 1 Schematic of the tribocorrosion tester. 
In order to evaluate the effect of wear-accelerated-corrosion for $316 \mathrm{~L}$, the electrochemical measurements were carried out using the electrochemical workstation. The electrochemical measurements are as follows: (1) for open circuit potential (OCP), the variation of OCP curves before, during and after sliding was monitored using the electrochemical workstation to study the depassivation-repassivation behavior of $316 \mathrm{~L}$ under tribocorrosion tests. (2) Potentiodynamic polarization measurements were performed by changing the potential of the reference electrode $(\mathrm{Ag} / \mathrm{AgCl})$ automatically from $-0.6 \mathrm{~V}$ to $0.7 \mathrm{~V}$ at a scanning rate of $2 \mathrm{mV} \mathrm{s}^{-1}$. (3) Electrochemical corrosion was tested on the worn surface of $316 \mathrm{~L}$. In addition, electrochemical impedance spectroscopic studies were carried out in the frequency range of $10 \mathrm{~Hz}$ to $100 \mathrm{kHz}$ with voltage amplitude of $10 \mathrm{mV}$. After the electrochemical measurements, the electrochemical results of corrosion potential $\left(E_{\text {corr }}\right)$, pitting potential $\left(E_{\text {pit }}\right)$, and corrosion current density $\left(I_{\text {corr }}\right)$ were calculated and the results are summarized in Table 1. Furthermore, all the tribocorrosion measurements were performed in artificial seawater at room temperature and in an air environment, and all the tests were performed at least three times and the average values were recorded.

\subsection{Microstructure characterization}

The worn surfaces and cross-surface morphology of 316L were observed using a laser confocal microscope (Leiss LCM700, Germany) and field emission scanning electron microscope (SEM, FEI Quanta 250 FEG, US) equipped with an energy dispersive spectrometer (EDS). The evolution of the phase composition on worn surfaces was determined using D8 advance X-ray diffraction (XRD, Bruker AXS) with $\mathrm{Cu}-\mathrm{K} \alpha$ radiation, the scanning speed was $6^{\circ} \mathrm{min}^{-1}$ and the scan angle range was $20-90^{\circ}$. Furthermore, the variation of martensite in weight after sliding under different conditions was calculated from the integrated intensities of martensite phases ${ }^{8}$ using the following equation:

$$
W_{\alpha}=\frac{I_{\alpha}}{\left(I_{\alpha}+0.942 I_{\mathrm{A}}\right)}
$$

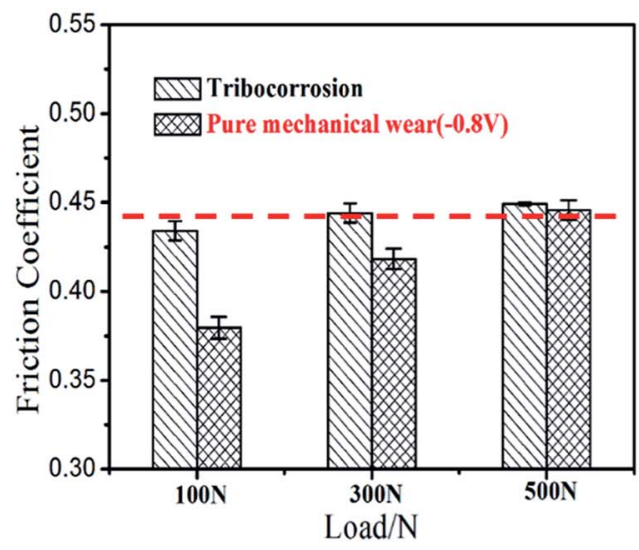

(a) Friction coefficient
$I_{\alpha}$ represents the integrated intensity of the peak in martensite (110) and $I_{\mathrm{A}}$ is the integrated intensity of the peak in austenite (111). Furthermore, the polished worn surfaces of the $316 \mathrm{~L}$ specimens were etched with $3 \mathrm{~mL} \mathrm{HCl}, 12 \mathrm{~mL} \mathrm{H}_{2} \mathrm{O}$ and $1 \mathrm{~g} \mathrm{FeCl}_{3}$ for $30 \mathrm{~s}$, which is conducive to distinguishing martensite and austenite. In addition, the microhardness of the worn surface was determined using a microhardness tester; the load was $300 \mathrm{~g}$ and the time was $10 \mathrm{~s}$. All the microhardness tests were performed at least ten times and the average value was calculated.

\section{Results and discussion}

\subsection{Tribocorrosion behavior of AISI 316L}

The variation of the friction coefficient and wear rate of AISI 316L in artificial seawater and cathodic protection conditions with different loads is shown in Fig. 2. In artificial seawater conditions, it could be observed that the average friction coefficient of 316L increases slightly with an increase in load, and the friction coefficient in cathodic protection conditions shows the same trend. In addition, the friction coefficient in cathodic protection conditions is much lower than that in seawater, particularly at low loads. Furthermore, the wear rate of $316 \mathrm{~L}$ decreases first and then increases with load in artificial seawater and cathodic protection conditions, and the wear rate in cathodic protection conditions is clearly lower than that in seawater conditions. Thus, it could be deduced that the damage of $316 \mathrm{~L}$ is aggravated due to corrosive seawater and the lubricating properties of seawater are also deteriorated due to corrosion.

The phase composition of the worn surface on 316L after sliding in artificial seawater and cathodic protection conditions was tested using XRD, as shown in Fig. 3. First, it is clear that the diffraction peaks of $316 \mathrm{~L}$ could be ascribed to the austenite phase (PDF-33-0397). However, the phase composition of the worn surface on $316 \mathrm{~L}$ is significantly altered after tribocorrosion tests, and the appearance of (110), (200) and (211) peaks clearly demonstrate that the worn surface consists of $\alpha^{\prime}$-martensite and austenite. In addition, the weight ratio of $\alpha^{\prime}$-martensite and

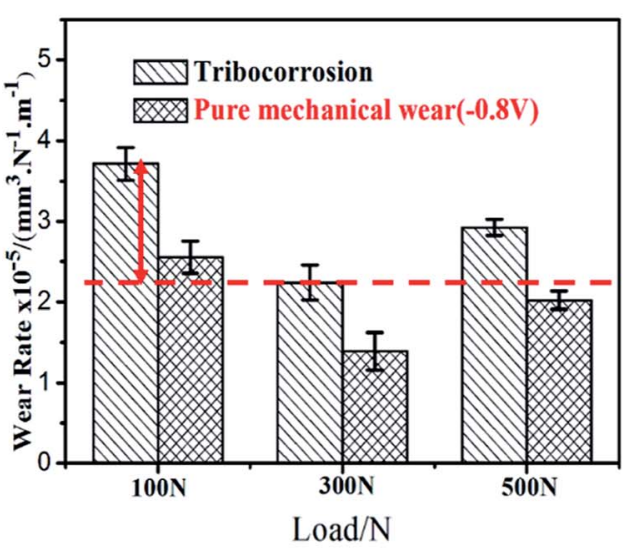

(b) Wear rate

Fig. 2 Tribocorrosion behavior of 316L under different loads. 
austenite is estimated using eqn (2), and the results show that the contents of $\alpha^{\prime}$-martensite increase with increase in load, which is in agreement with the literature. ${ }^{27}$ Furthermore, the contents of $\alpha^{\prime}$-martensite in cathodic protection conditions are higher than that in seawater after sliding under the same loads, which could be attributed to the fact that the corrosion resistance of $\alpha^{\prime}$-martensite is poorer than austenite.

The microhardness of the worn surface on 316L after sliding in artificial seawater and cathodic protection conditions is shown in Fig. 4. The results indicate that the microhardness of 316L is clearly low (284.1 HV). After sliding, the microhardness of the worn surface increases with load. For example, the microhardness of $316 \mathrm{~L}$ in cathodic protection conditions after sliding under $500 \mathrm{~N}$ increases up to $424.6 \mathrm{HV}$, which is clearly higher than $316 \mathrm{~L}$ in the initial state. According to the XRD results, it could be deduced that the significant increase in hardness of $316 \mathrm{~L}$ could be attributed to the formation of $\alpha^{\prime}$-martensite, which is clearly higher than austenite. ${ }^{28}$

\subsection{Electrochemical results of AISI 316L}

Fig. 5 clearly represents the evolution of OCP for 316L steel before, during and after the tribocorrosion testing with different loads in artificial seawater. Before the sliding tests, the OCP of $316 \mathrm{~L}$ steel was high and stable with the increase in immersion time, which is ascribed to the formation of a relatively dense passive film. During sliding, the OCP of $316 \mathrm{~L}$ shifted negatively by $500 \mathrm{mV}$, compared to that of the OCP in static conditions, indicating that the passive film was broken during sliding. Thus, the contingent negative variation of OCP during sliding could be attributed to the rapid damage of passive film caused due to wear. In addition, potential values are negatively shifted with the increase in contact load, presumably owning to the more severe damage in the passive film. Furthermore, the OCP increases immediately after sliding, but it could not reach the original potential value in static conditions. This could be attributed to the formation of $\alpha^{\prime}$-martensite on the worn surface. Furthermore, the potential of $\alpha^{\prime}$-martensite is more negative than austenite, and the

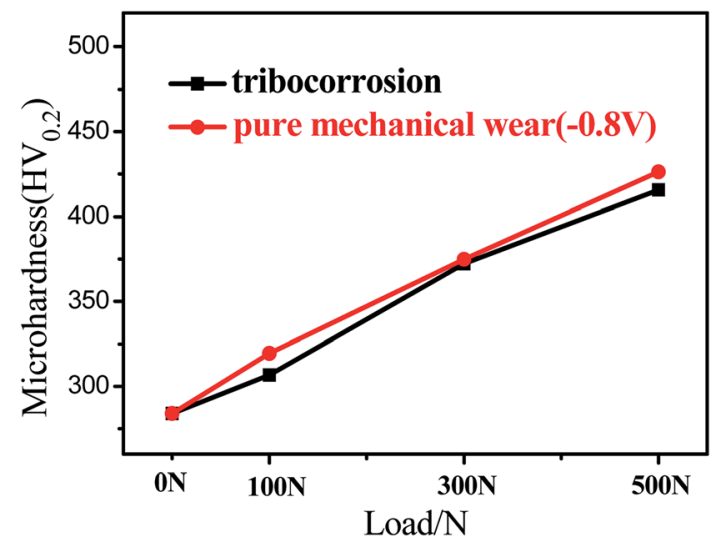

Fig. 4 Microhardness of the worn surface on $316 \mathrm{~L}$ after sliding in artificial seawater and cathodic protection conditions.

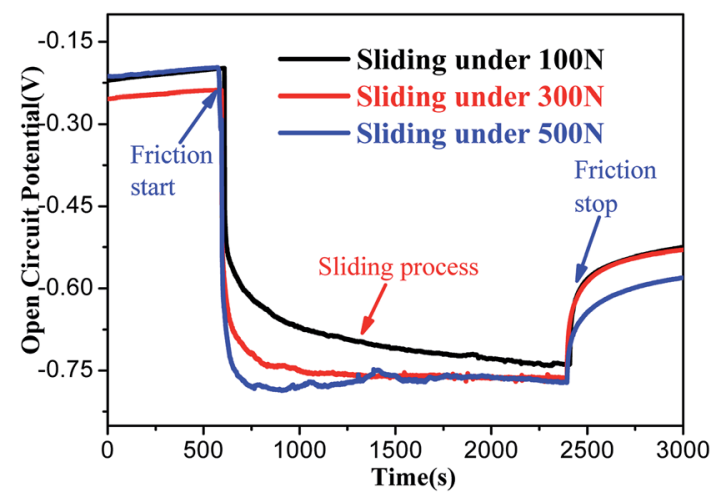

Fig. 5 Open circuit potential of $316 \mathrm{~L}$ in different states of the tribocorrosion process under different loads.

corrosion tendency of the worn surface after tribocorrosion tests also increased.

In order to study the influence of microstructure evolution on the corrosion behaviors of AISI 316L in artificial seawater, the dynamic potential polarization curve of $316 \mathrm{~L}$ after sliding in artificial seawater under different loads was evaluated using the

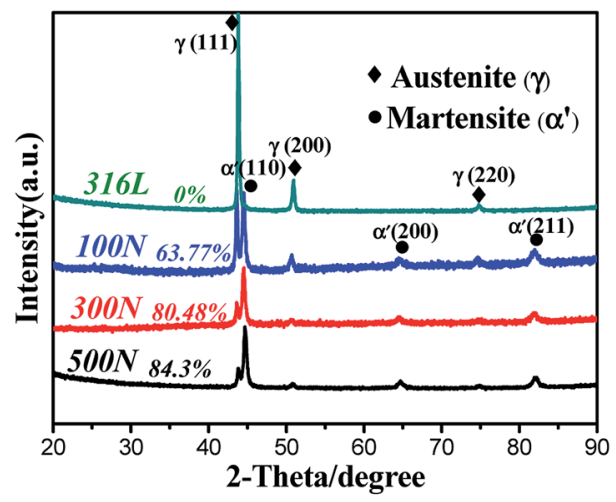

(a) Artificial seawater condition

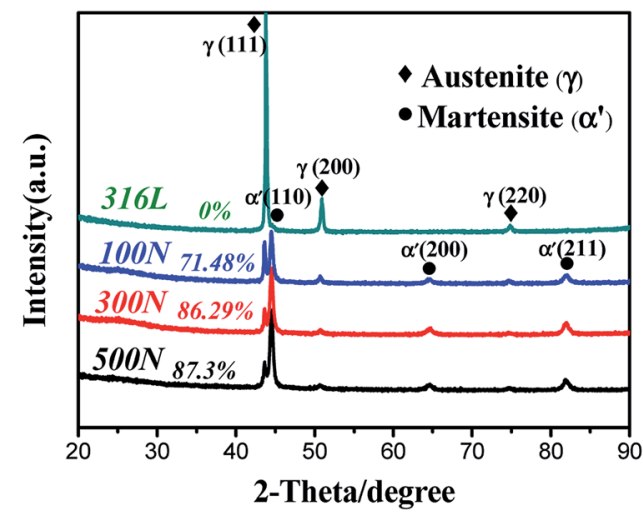

(b) Cathodic protection condition

Fig. 3 XRD patterns of the worn surface on $316 \mathrm{~L}$ after sliding in artificial seawater (a) and cathodic protection conditions (b). 
electrochemical workstation; the resultant polarization curves are shown in Fig. 6. Corrosion current density $\left(I_{\text {corr }}\right)$, corrosion potential $\left(E_{\text {corr }}\right)$ and pit potential $\left(E_{\text {pit }}\right)$ were extracted from the polarization curve using the Tafel extrapolation method, and the results are listed in Table 1. From the electrochemical results, it is observed that the corrosion potential of the worn surface shifted negatively about $100 \mathrm{mV}$ compared to 316L. Moreover, with the increase in load, the $I_{\text {corr }}$ values rise from $0.696 \times 10^{-1} \mu \mathrm{A}$ to $0.354 \mu \mathrm{A}$. According to the phase composition of the worn surface, a larger amount of $\alpha^{\prime}$-martensite leads to a negative shift of $E_{\text {corr }}$. In addition, the content of $\alpha^{\prime}$-martensite increases with load; thus, the corrosion resistance of 316L decreases with load. Therefore, the worn surface of 316L exhibits a lower passive current density and wider passive region, indicating that the surface composition is affected by the formation of $\alpha^{\prime}$-martensite. In addition, the $E_{\text {pit }}$ is about $300 \mathrm{mV}(\mathrm{Ag} / \mathrm{AgCl})$ for the worn surface of $316 \mathrm{~L}$ and it is $489 \mathrm{mV}$ for $316 \mathrm{~L}$ in static corrosion, demonstrating that the $E_{\mathrm{pit}}$ of the worn surface rapidly decreases with the change in sliding conditions. Furthermore, it could be confirmed that the corrosion resistance of 316L in artificial seawater diminished, based on the microstructure evolution in tribocorrosion tests.

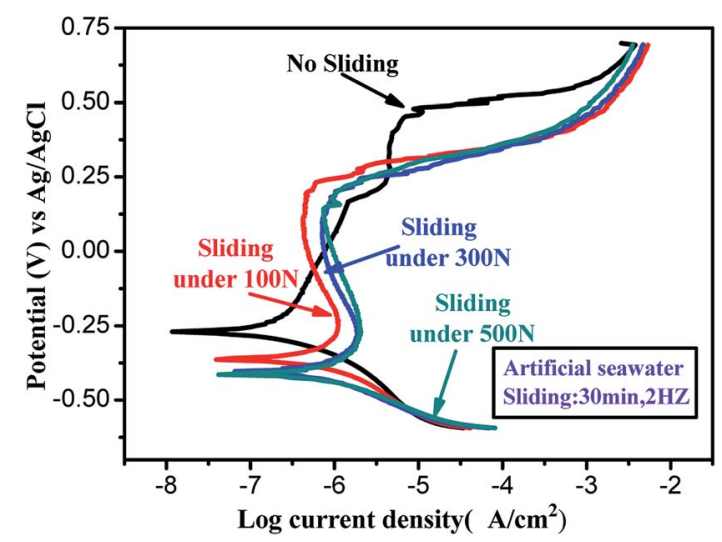

Fig. 6 Dynamic potential polarization curve of 316L after sliding in artificial seawater under different loads.
Nyquist and Bode plots of the worn surface area on 316L stainless steel under different loads are shown in Fig. 7, and the results of the electrochemical are presented in Table 1. Electrochemical impedance spectroscopy (EIS) also explains the variation of corrosion resistance with load. Generally, the impedance values at low frequencies are considered as an indicator for anti-corrosion performance. At $0.01 \mathrm{~Hz}$, the impedance values of the worn surface under $0 \mathrm{~N}, 100 \mathrm{~N}, 300 \mathrm{~N}$ and $500 \mathrm{~N}$ are $619.95 \mathrm{k} \Omega \mathrm{cm}^{2}, 280.68 \mathrm{k} \Omega \mathrm{cm}^{2}, 128.74 \mathrm{k} \Omega \mathrm{cm}^{2}$ and $126.28 \mathrm{k} \Omega \mathrm{cm}^{2}$, respectively, indicating that the corrosion resistance of the worn surface on 316L decreases with load and has nearly optimal performance in the static corrosion state. In addition, the phase peak and phase angle of the worn surface decreases slightly when compared with $316 \mathrm{~L}$ in the static corrosion state, confirming that more electric charges accumulated on the worn surface and the corrosion rate of $316 \mathrm{~L}$ is also accelerated on sliding in seawater.

Typical Nyquist impedance plots of the worn surface on 316L in artificial seawater were also obtained using an electrochemical workstation, demonstrating the influence of the microstructure evolution on the impedance behavior of the worn surface. From Fig. 7b, it could be observed that all the Bode plots decrease with load, and it presents the same capacitive semi-circles. Furthermore, the $\alpha_{\mathrm{OX}}, Q_{\mathrm{OX}}, R_{\mathrm{OX}}$ and $R_{\mathrm{E}}$ parameters were obtained using the fitting procedure of $\mathrm{R} / / \mathrm{CPE}$ as listed in Table 2. It could be observed that the $Q_{\text {ox }}$ value increases and $R_{\mathrm{OX}}$ decreases with an increase in load, confirming that the charge transfer velocities rapidly increase and the passive films are affected due to the formation of

Table 2 Fitting parameters of R//CPE for the worn surface of $316 \mathrm{~L}$ in artificial seawater

\begin{tabular}{lllll}
\hline Load $/ \mathrm{N}$ & $0 \mathrm{~N}$ & $100 \mathrm{~N}$ & $300 \mathrm{~N}$ & $500 \mathrm{~N}$ \\
\hline$\alpha_{\mathrm{OX}}\left(10^{-5} \Omega^{-1} \mathrm{~S}^{n} \mathrm{~cm}^{2}\right)$ & 0.95 & 0.91 & 0.89 & 0.89 \\
$Q_{\mathrm{Ox}}\left(\mathrm{k} \Omega \mathrm{cm}^{2}\right)$ & 1.139 & 2.171 & 3.524 & 4.550 \\
$R_{\mathrm{OX}}\left(\Omega \mathrm{cm}^{2}\right)$ & 974.6 & 821.6 & 417.5 & 318.4 \\
$R_{\mathrm{E}}$ & 73.88 & 73.45 & 72.07 & 69.91
\end{tabular}

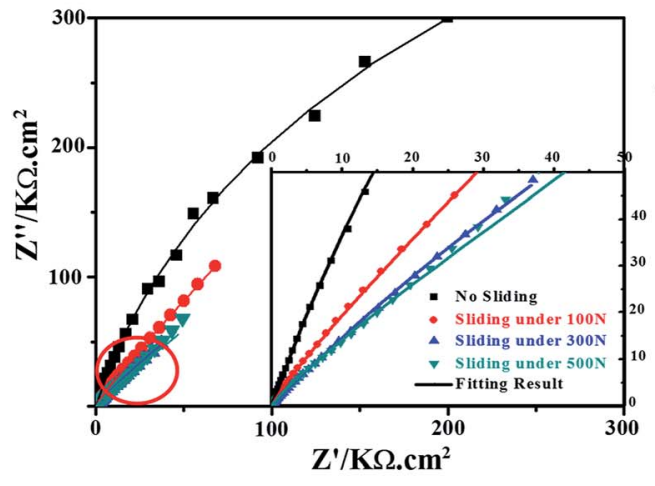

(a) Nyquist plot

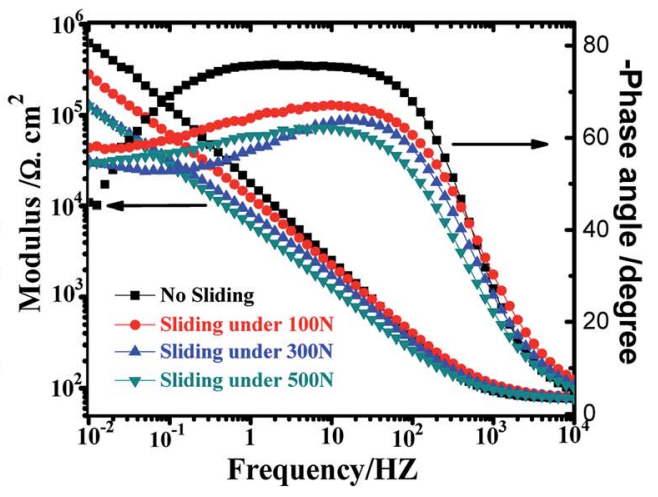

(b) Bode

Fig. 7 Nyquist and Bode plots of the worn surface on 316L stainless steel under different loads. 
$\alpha^{\prime}$-martensite. Therefore, it could be deduced that a galvanic corrosion is formed due to martensite and austenite on the worn surface; thus, the corrosion rate of $316 \mathrm{~L}$ is aggravated due to the formation of martensite under different loads.

\subsection{Microstructure evolution}

The worn surface of 316L after sliding in artificial seawater and cathodic protection condition was observed using SEM and confocal laser scanning microscopy, and the corresponding images are shown in Fig. 8. It could be observed that the worn surface of $316 \mathrm{~L}$ is covered by a large number of grooves and wear debris. In lower load conditions, the grooves are shallower and narrower. With an increase in load, the grooves become broader and deeper, and a series of spalling and tearing appears on the worn surface at higher load conditions (500 N). Furthermore, the 3D image also indicates that the grooves become broader and deeper with load. The wear mechanism of $316 \mathrm{~L}$ at $100 \mathrm{~N}$ is dominated by abrasive wear. Thus, abrasive wear and adhesive wear are the main wear mechanisms of $316 \mathrm{~L}$ at $300 \mathrm{~N}$ and $500 \mathrm{~N}$. In cathodic protection conditions, the worn surface of $316 \mathrm{~L}$ becomes smoother than in seawater after sliding, confirming that the passive film on the worn surface
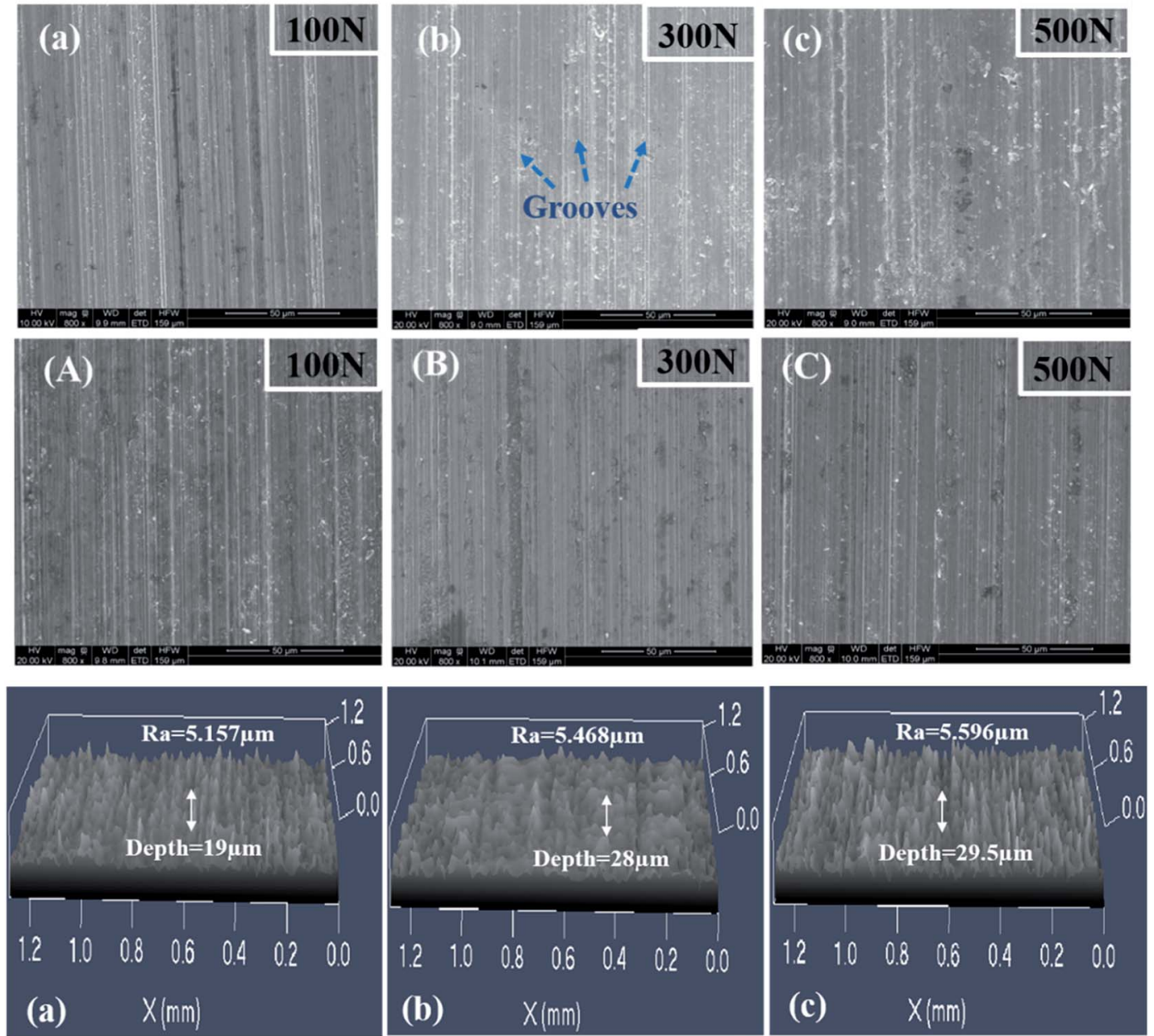

(a) $\quad X(\mathrm{~mm})$
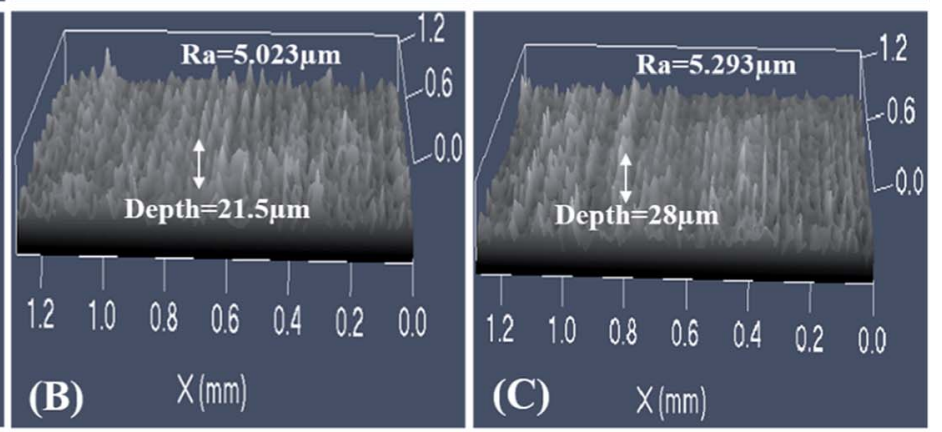

Fig. 8 SEM images and confocal laser scanning microscopy acquired 3D images of the worn surface on 316L under different loads in artificial seawater (a)-(c) and cathodic protection conditions (A)-(C). 
could be easily removed due to corrosion in seawater. Thus, the wear damage of 316L increases during exposure to seawater, owing to the corrosion accelerated wear, wear accelerated corrosion and synergetic contributions of corrosion and wear.

In order to study the distribution of martensite on the worn surface, a metallographic etchant $\left(1 \mathrm{~g} \mathrm{FeCl}_{3}, 3 \mathrm{~mL} \mathrm{HCl}, 12 \mathrm{~mL}\right.$ $\mathrm{H}_{2} \mathrm{O}$ ) was used to etch the worn surface of $316 \mathrm{~L}$, and the related SEM images are shown in Fig. 9. It could be observed that the worn surface is composed of polygonal austenite and lath martensite, and the content of lath martensite clearly increases with load. Combined with XRD results, it could be deduced that the surface strain increases with load; thus, the contents of strain-induced martensite are much higher at high load conditions. Therefore, the hardness and wear resistance of austenitic stainless steel are significantly improved due to the formation of martensite, but the corrosion resistance also deteriorates at the same time. Therefore, the tribocorrosion behavior of austenitic stainless steel with metastable austenite is dominated by the balance of formation and corrosion of martensite, such as that observed in AISI 304 and 316L austenitic stainless steel.

The worn surface of the $\mathrm{Al}_{2} \mathrm{O}_{3}$ disc after sliding in artificial seawater is shown in Fig. 10. During sliding, the worn surface of the $\mathrm{Al}_{2} \mathrm{O}_{3}$ disc is mainly covered by the massive adhesion, which is formed by the transfer of the $316 \mathrm{~L}$ pin. With the increase in load, the area of massive adhesion clearly increases, and it becomes smoother and covers the entire surface of the disc. Thus, the worn surface of the $\mathrm{Al}_{2} \mathrm{O}_{3}$ disc also confirms that the wear mechanisms of $316 \mathrm{~L}$ are adhesive wear and abrasive wear. Therefore, increasing hardness is beneficial for the antiadhesive and anti-scratch effects, thus improving the wear resistance of 316L.

\subsection{Synergistic effect of corrosion and wear}

During tribocorrosion tests, the tribocorrosion properties of $316 \mathrm{~L}$ are not only affected due to the variation of the phase composition on the worn surface but also due to the significant variation in the corrosion resistance with the formation of strain-induced martensite. Therefore, the degradations due to chemical and mechanical mechanisms of $316 \mathrm{~L}$ are not independent of each other during tribocorrosion tests; thus, the synergetic contributions of mechanical wear and corrosion as well as the total mass loss of AISI 316L under different loads in artificial seawater were calculated according to the ASTM G11909 standard. In static seawater, the corrosion rate of $316 \mathrm{~L}$ is very low, and is considered as negligible in this study. Thus, the damage of 316L during sliding in seawater is composed of pure mechanical wear loss $\left(W_{0}\right)$. The effect of corrosion on wear $\left(S^{\prime}\right)$ and the effect of wear on corrosion $\left(S^{\prime \prime}\right)$ are summarized in

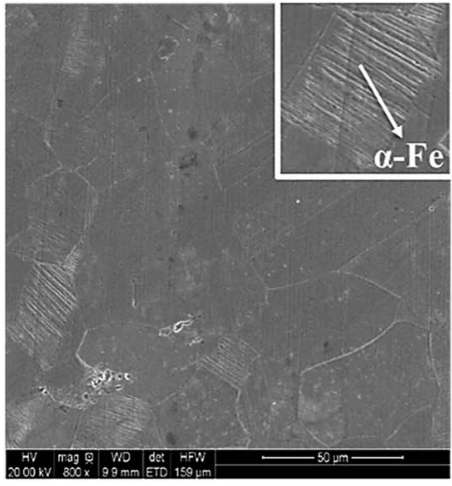

(a) $100 \mathrm{~N}$

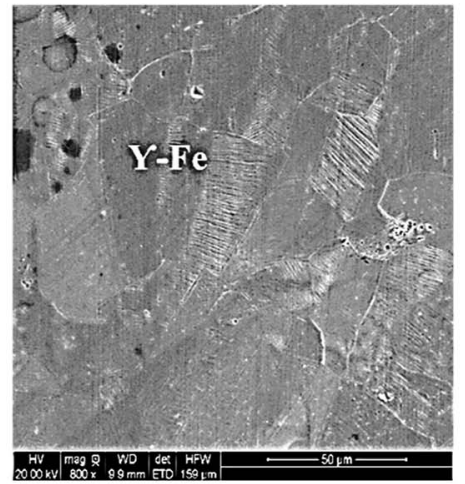

(b) $300 \mathrm{~N}$

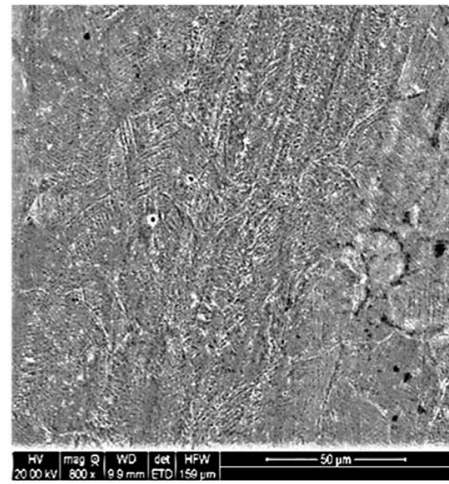

(c) $500 \mathrm{~N}$

Fig. 9 SEM images of the etched worn surface of $316 \mathrm{~L}$ under different loads in artificial seawater.

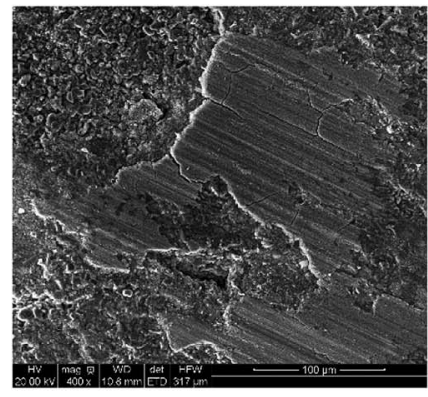

(a) $100 \mathrm{~N}$

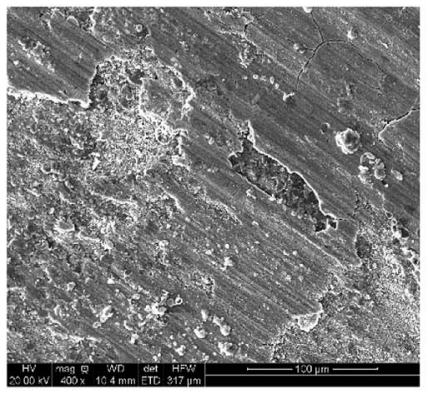

(b) $300 \mathrm{~N}$

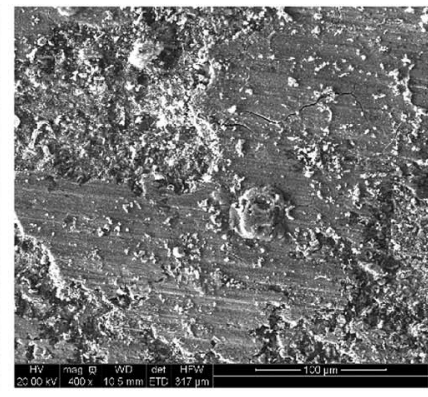

(c) $500 \mathrm{~N}$

Fig. 10 Worn surface of $\mathrm{Al}_{2} \mathrm{O}_{3}$ disc under different loads in artificial seawater. 
Table 3 Synergetic contributions of pure mechanical wear and corrosion and total mass loss of AISI 316L under different loads in artificial seawater

\begin{tabular}{lllllll}
\hline & \multicolumn{2}{l}{ Material loss rate $\left(\mathrm{mm}^{3}\right.$ per $\mathrm{mm}^{2}$ per year $)$} & & \\
\cline { 2 - 7 } Load/N & $T$ & $W_{0}$ & $C_{0}$ & $C_{\mathrm{W}}$ & $S$ & $S^{\prime}$ \\
\hline $100 \mathrm{~N}$ & 117.13 & 80.46 & $7.2 \times 10^{-4}$ & 1.77 & 36.67 & 34.90 \\
$300 \mathrm{~N}$ & 211.970 & 131.730 & $7.2 \times 10^{-4}$ & 2.590 & 80.240 & 1.77 \\
$500 \mathrm{~N}$ & 461.05 & 318.35 & $7.2 \times 10^{-4}$ & 2.95 & 142.70 & 1.590 \\
\end{tabular}
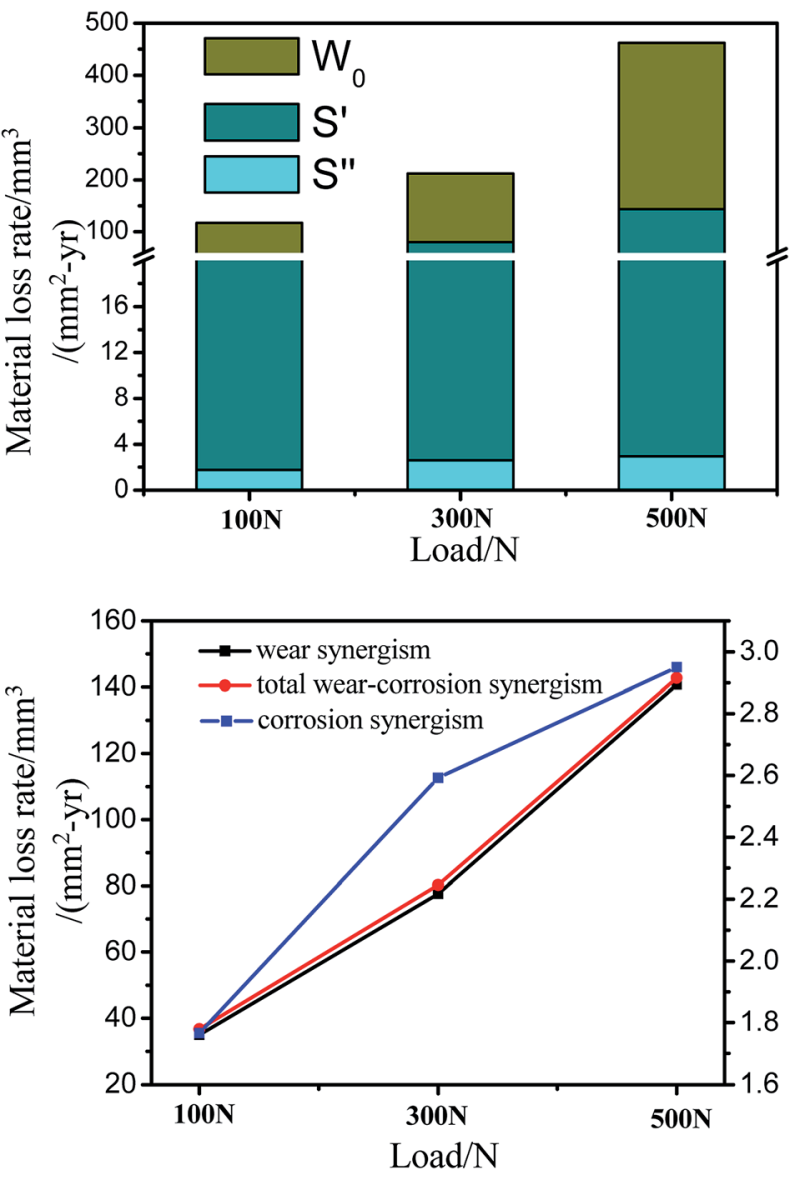

Fig. 11 (a) Synergetic contributions of mechanical wear and corrosion and (b) total mass loss of $316 \mathrm{~L}$ at different loads in artificial seawater.

Table 3 and Fig. 11 a. From the obtained results, it could be observed that the mass loss of $316 \mathrm{~L}$ in seawater is chiefly dominated by mechanical wear; thus, the wear resistance of $316 \mathrm{~L}$ is significantly improved due to the formation of martensite on the worn surface. In addition, the effect of corrosion on wear $\left(S^{\prime}\right)$ is significantly greater than the effect of wear on corrosion $\left(S^{\prime \prime}\right)$, confirming that the primary damage to $316 \mathrm{~L}$ in seawater is caused due to the mechanical wear and the effect of corrosion on wear. Furthermore, the wear resistance of 316L improved due to the formation of martensite, and the corrosion resistance of $316 \mathrm{~L}$ deteriorated due to the galvanic corrosion of martensite and austenite. Thus, the formation and corrosion of strain-induced-martensite is the key factor restricting the improvement of the tribocorrosion properties of austenitic stainless steel, such as 316L.

The synergistic effect of corrosion and wear of 316L under different loads in artificial seawater are shown in Fig. 11b. The results indicate that the total mass loss and the effect of corrosion on the wear of $316 \mathrm{~L}$ increase with load, and the total mass loss is determined by the pure mechanical wear. Under higher load conditions, the formation of strain-inducedmartensite occurs more easily than in lower load conditions; thus, the mechanical properties such as the hardness of the worn surface tend to be deteriorated by martensite due to poor corrosion resistance. Therefore, a higher load means higher strain on the worn surface, which is beneficial for the transformation of austenite to strain-induced martensite.

It should be pointed out that the effect of strain-induced martensite on the tribocorrosion behavior of AISI 316L is significant and complicated. According to this research, it could be judged that the role of strain-induced martensite on the tribocorrosion of austenitic stainless steel is relatively clear, that is, the formation of martensite increases the hardness of the worn surface and improves the wear resistance of $316 \mathrm{~L}$. However, the corrosion resistance of $316 \mathrm{~L}$ in seawater is deteriorated due to the macroscopic and microscopic galvanic corrosion of martensite and austenite. During tribocorrosion tests, the increase in load means higher strain deformation on the worn surface. Thus, the contents of strain-induced martensite increased significantly and the wear resistance of austenitic stainless steel also improved efficiently due to the formation of martensite. Moreover, microscopic galvanic corrosion has been established with the coexistence of martensite and austenite on the worn surface, and it is exacerbated under higher load. Therefore, the corrosion, wear, corrosion accelerated wear and wear accelerated corrosion are dominated by the formation and corrosion of strain-inducedmartensite in $316 \mathrm{~L}$ with metastable austenite.

\section{Conclusions}

In this study, the effect of strain-induced martensite on the tribocorrosion of AISI 316L austenitic stainless steels in seawater was investigated in artificial seawater. The tribocorrosion behaviors, microstructure evolution and synergistic effect of corrosion and wear of AISI 316L were analyzed, and the key conclusions were drawn as follows:

1. The transformation of austenite to martensite is the main microstructure evolution of AISI 316L after sliding in seawater. 
A high load means high strain deformation of the worn surface, which is beneficial for the formation of strain-induced martensite. Thus, the hardness and wear resistance of AISI $316 \mathrm{~L}$ is closely related to the increasing content of martensite.

2. Macroscopic and microscopic galvanic corrosion is formed due to martensite (strain-induced martensite) and retained austenite on the worn surface; thus, the stability and integrity of passivation film on the worn surface of $316 \mathrm{~L}$ is influenced by the transformation of austenite to strain-induced martensite.

3. The total mass loss of $316 \mathrm{~L}$ in artificial seawater is mainly due to mechanical wear and the synergistic effect of corrosion on wear particularly in high load conditions. Thus, the tribocorrosion behavior of austenitic stainless steel is dominated by the formation and corrosion of strain-induced-martensite in austenitic stainless steel with metastable austenite.

\section{Conflicts of interest}

There are no conflicts to declare.

\section{Acknowledgements}

The authors acknowledge the financial supports by the National Natural Science Foundation of China (Grant No. 51705415 \& 11502196), National Basic Research Program of China (Grant No. 2014CB643302) National Key R\&D Program (Grant No. 2016YFB0300604) and Ningbo Municipal Nature Science Foundation (Grant No. 2017A610007).

\section{References}

1 H. S. Khatak and B. Raj, Corrosion of austenitic stainless steels: mechanism, mitigation and monitoring, Alpha Science International Ltd, India, 2002.

2 Y. Zhang, X. Yin, J. Wang and F. Yan, Influence of microstructure evolution on tribocorrosion of $304 \mathrm{SS}$ in artificial seawater, Corros. Sci., 2014, 88, 423-433.

$3 \mathrm{Y}$. Sun and R. Bailey, Improvement in tribocorrosion behavior of 304 stainless steel by surface mechanical attrition treatment, Surf. Coat. Technol., 2014, 253, 284-291.

4 P. A. Dearnley and G. Aldrich-Smith, Corrosion-wear mechanisms of hard coated austenitic 316L stainless steels, Wear, 2004, 256, 491-499.

5 Y. Zhang, X. Yin, J. Wang and F. Yan, Influence of potentials on the tribocorrosion behavior of 304SS in artificial seawater, RSC Adv. , 2014, 4, 55752-55759.

6 C. O. A. Olsson and D. Landolt, Passive films on stainless steels-chemistry, structure and growth, Electrochim. Acta, 2003, 48, 1093-1104.

7 M. J. Carmezim, A. M. Simões, M. F. Montemor and M. D. Cunha Belo, Capacitance behaviour of passive films on ferritic and austenitic stainless steel, Corros. Sci., 2005, 47, 581-591.

8 J. Chen, J. Wang, F. Yan, Q. Zhang and Q. Li, Effect of applied potential on the tribocorrosion behaviors of Monel K500 alloy in artificial seawater, Tribol. Int., 2015, 81, 1-8.
9 J. Chen, Q. Zhang, Q.-a. Li, S.-l. Fu and J.-z. Wang, Corrosion and tribocorrosion behaviors of AISI 316 stainless steel and Ti6Al4V alloys in artificial seawater, Trans. Nonferrous Met. Soc. China, 2014, 24, 1022-1031.

10 N. Diomidis, J. P. Celis, P. Ponthiaux and F. Wenger, Tribocorrosion of stainless steel in sulfuric acid: identification of corrosion-wear components and effect of contact area, Wear, 2010, 269, 93-103.

11 Y. Sun and V. Rana, Tribocorrosion behaviour of AISI 304 stainless steel in $0.5 \mathrm{M} \mathrm{NaCl}$ solution, Mater. Chem. Phys., 2011, 129, 138-147.

12 Y. Zhang, X. Yin, Y. Yan, J. Wang and F. Yan, Tribocorrosion behaviors of 304SS: effect of solution pH, RSC Adv., 2015, 5, 17676-17682.

13 A. Leyland and A. Matthews, On the significance of the $\mathrm{H} / \mathrm{E}$ ratio in wear control: a nanocomposite coating approach to optimised tribological behaviour, Wear, 2000, 246, 1-11.

14 P. J. Burnett and D. S. Rickerby, The relationship between hardness and scratch adhesion, Thin Solid Films, 1987, 154, 403-416.

15 T. S. Eyre, Wear characteristics of metals, Tribol. Int., 1976, 9, 203-212.

16 T. Gladman, Precipitation hardening in metals, Mater. Sci. Technol., 1999, 15, 30-36.

17 H. Y. Yi, F. K. Yan, N. R. Tao and K. Lu, Work hardening behavior of nanotwinned austenitic grains in a metastable austenitic stainless steel, Scr. Mater., 2016, 114, 133-136.

18 Y. Yamamoto, G. Muralidharan and M. P. Brady, Development of L12-ordered $\mathrm{Ni}_{3}(\mathrm{Al}, \mathrm{Ti})$-strengthened alumina-forming austenitic stainless steel alloys, Scr. Mater., 2013, 69, 816-819.

19 F. K. Yan, N. R. Tao, F. Archie, I. Gutierrez-Urrutia, D. Raabe and K. Lu, Deformation mechanisms in an austenitic singlephase duplex microstructured steel with nanotwinned grains, Acta Mater., 2014, 81, 487-500.

20 Y. Estrin and A. Vinogradov, Extreme grain refinement by severe plastic deformation: a wealth of challenging science, Acta Mater., 2013, 61, 782-817.

21 G. Han, P. Jiang, J. Wang and F. Yan, Effects of $\mathrm{NaCl}$ concentration on wear-corrosion behavior of SAF 2507 super duplex stainless steel, RSC Adv., 2016, 6, 111261111268.

22 M. C. Park, K. N. Kim, J. Y. Yun, G. S. Shin and S. J. Kim, Strain-Induced $\varepsilon / \alpha^{\prime}$ Martensitic Transformation Behavior and Solid Particle Erosion Resistance of Austenitic $\mathrm{Fe}-\mathrm{Cr}-$ C-Mn/Ni Alloys, Tribol. Lett., 2014, 54, 51-58.

23 S. M. Alvarez, A. Bautista and F. Velasco, Influence of straininduced martensite in the anodic dissolution of austenitic stainless steels in acid medium, Corros. Sci., 2013, 69, 130138.

24 S. Djaziri, Y. Li, G. A. Nematollahi, B. Grabowski, S. Goto, C. Kirchlechner, et al., Deformation-Induced Martensite: A New Paradigm for Exceptional Steels, Adv. Mater., 2016, 28, 7753-7757.

25 M. Shirdel, H. Mirzadeh and M. H. Parsa, Nano/ultrafine grained austenitic stainless steel through the formation and reversion of deformation-induced martensite: 
mechanisms, microstructures, mechanical properties, and TRIP effect, Mater. Charact., 2015, 103, 150-161.

26 C. Ye, A. Telang, A. S. Gill, S. Suslov, Y. Idell, K. Zweiacker, et al., Gradient nanostructure and residual stresses induced by ultrasonic nano-crystal surface modification in 304 austenitic stainless steel for high strength and high ductility, Mater. Sci. Eng., A, 2014, 613, 274-288.
27 M. Hua, X. Wei and L. Jian, Friction and wear behavior of SUS 304 austenitic stainless steel against $\mathrm{Al}_{2} \mathrm{O}_{3}$ ceramic ball under relative high load, Wear, 2008, 265, 799-810.

28 B. Zhang, J. Wang, Y. Zhang, G. Han and F. Yan, Comparison of tribocorrosion behavior between 304 austenitic and 410 martensitic stainless steels in artificial seawater, RSC Adv., 2016, 6, 107933-107941. 